\title{
Rehabilitation with implants simultaneously to mandible fracture treatment. Follow up of 18 months
}

\author{
Pâmela Letícia dos Santos ${ }^{1 *}$, Lamis Meorin-Nogueira², Danilo Louzada-de Oliveira ${ }^{3}$, \\ Maria del Pilar Rodriguez-Sanchez ${ }^{4}$, Jéssica Lemos-Gulinelli ${ }^{5}$, Idelmo Rangel Garcia Junior ${ }^{6}$
}

\begin{abstract}
1. DDS, MSc, PhD in Oral and Maxillofacial Surgery and Traumatology. Professor, Department of Health Sciences, Implantology Post Graduation Course, Dental School, University Center of Araraquara, UNIARA, Araraquara, SP, Brazil.

2. DDS, MSc, PhD in Oral and Maxillofacial

Surgery, Universidade Estadual Paulista, (UNESP) Araçatuba, São Paulo, Brazil.

3. DDS, MSc, PhD student in Oral and Maxillofacial Surgery, Universidade do Sagrado Coração - USC, Bauru, São Paulo, Brazil.

4. DDS, MSc, PhD in Implantology - Programa de Odontologia de la Universidad del Sinú "Elias Bechara Zainum" de Montería -Colombia. 5. DDS, MSc, PhD, Assistant Professor, Discipline of Oral and Maxillofacial Surgery and Implantology, Universidade do Sagrado Coração - USC, and Assistant Professor, Implantology Post graduation Course, USC, Bauru, São Paulo, Brazil.

6. DDS, MSc, PhD, Assistant Professor Disciplines of Surgery and Integrated Clinic, Discipline of Oral and Maxillofacial Surgery, UNESP - Univ. Estadual Paulista, Araçatuba, São Paulo, Brazil.

* Corresponding Author: Pâmela Letícia dos Santos | Department of Health Sciences, University of Araraquara (UNIARA) Rua Carlos Gomes, 1338, Centro, Araraquara-SP / Brasil - CEP 14801-340| Phone: +(55)1430105494 | E-mail:pamelalsantos@ hotmail.com

Work received on 23/05/2017. Approved for publication on $27 / 08 / 2017$
\end{abstract}

\section{ABSTRACT}

Objective: This study was reduction of a bilateral mandibular fracture through the installation of dental implants with immediate loading, re-establishing the stomatognathic function of the patient. Case Report: A 58-year-old male patient seek the emergency room from hospital after suffering a motorcycle accident. After physical and imaging examinations was diagnosed with bilateral mandibular fracture. The treatment of choice, once the patient was edentulous, was the reduction and stabilization of the fracture with the installation of 5 dental implants with immediate loading. After 1 year of postoperative follow-up, the facial contour along with the occlusion were reestablished. Radiographically, it was found the proper placement of plates and screws with correct baseline realignment and maintenance of implant-supported prosthesis. Conclusion: In this case report with follow-up of 18 months, the functional prosthetic rehabilitation and immediate aesthetic with immediate loading system, after reduction and fixation of mandibular fractures proved to be a good treatment option.

KEYWORDS

Dental Implants; Fracture; Mandible.

Rev. Clin. Periodoncia Implantol. Rehabil. Oral Vol. 11(2); 109-111, 2018.

\section{INTRODUCTION}

The mandible can be considered the strongest and largest facial bone, but it is more susceptible to fractures due to its prominent position, mobility and anatomic configuration. The mandibular bone fractures occurring twice as frequently as fractures of the midface because of the less bone support ${ }^{(1)}$. These injuries are mostly related to a traumatic incident including traffic accident, interpersonal violence, sport injuries and falls ${ }^{(2)}$.

The maxillofacial fractures in the elderly has increased and show characteristics depending on its etiology, patterns and treatment modalities $^{(3)}$. Edentulous patients may have a higher rate of fractures of the mandibular body, which probably is due to the reduction in height and bone vascularization ${ }^{(4)}$.

The treatment possibilities of mandible fractures can be surgical and nonsurgical(5). Surgical procedure imply open reduction and internal fixation to restore masticatory function. Open reduction is indicated, especially in displaced fractures cases ${ }^{(2)}$

The objective of mandibular fracture treatment is to re-establish dental occlusion and masticatory function. However, in edentulous patient, it is difficult to re-establish dental occlusion, and dental implants have become a good treatment approach for that. In order to reduce the treatment time, as well as patient discomfort and postoperative care, the concept of immediate loading was developed to provide a good restoration of dentition after implant placement ${ }^{(6)}$. This kind of treatment provides a positive psychological effect on edentulous patient ${ }^{(7)}$.

A bone quantity and quality in the anterior area of the mandible can be considered as a region of high success rate in immediate implant loading and it is well documented in the literature the use of four implants placed between the mental foramen associated with the immediate loading using a fixed full-arch implant-supported acrylic resin prostheses ${ }^{(8)}$.

The aim of this article is to document a reduction of a bilateral mandibular fracture and dental implants installation with immediate loading during the same surgical procedure, to re-establish the stomatognathic function of the patient.

\section{CASE REPORT}

A 58-year-old male patient was attended at the emergency room of Araçatuba's hospital two days after suffering a motorcycle accident. The patient denied suffering from diabetes, immunocompromised disease, osteoporosis or smoking habits. Extraoral physical examination showed right hemifacial swelling with mandibular movements limitations. Intraoral examination showed abnormal mobility in the right mandibular body area and left mandibular angle. Through imaging exams it was diagnosed fracture at right mandibular body and left mandibular angle (Figure 1 e 2).

The treatment option, taking into account the edentulous condition of the patient was open reduction and internal fixation followed by four dental implants installation with immediate loading.

Surgical procedures were performed under general anesthesia, with nasotracheal intubation, local infiltrative anesthesia was performed in the fractures areas, using $2 \%$ lidocaine associated with epinephrine 1 : 200,000 , for the purpose of hemostasis. Then a trapezoidal paracrestal incision was made to expose the right mandibular body.

Then four implants (Conexão Sistema de Próteses, Arujá, São Paulo Brasil) of $4.1 \times 11.5 \mathrm{~mm}$ were installed between the mental foramen, and 1 implant of $4,1 \times 10 \mathrm{~mm}$ was installed in the right mandibular body posterior to the fracture line, all of them with installation torque of $60 \mathrm{~N} / \mathrm{cm}$. Then the reduction and fixation of mandibular fractures was performed. The right 

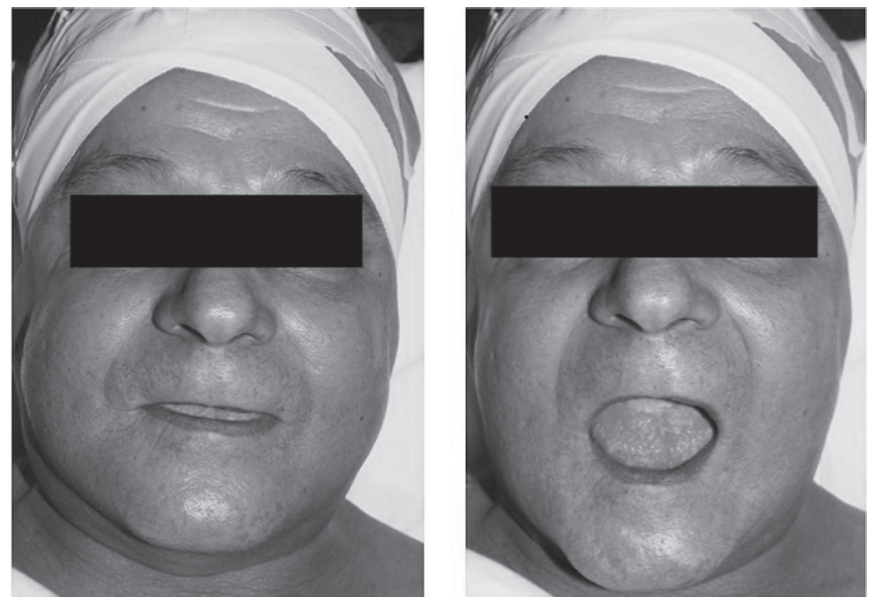

Figure 1. Preoperative - extra oral clinical aspect.

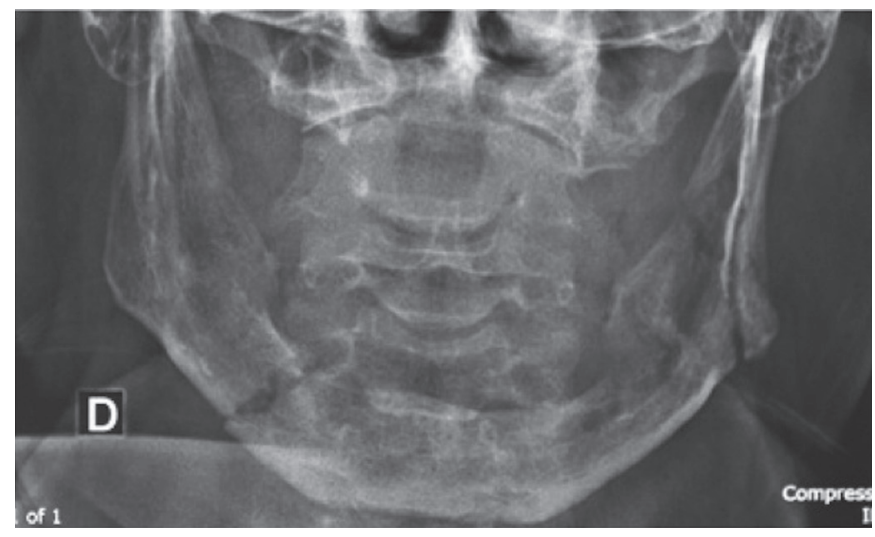

Figure 2. Preoperative - radiographs of the patient with a right mandibular body fracture and left mandibular angle fracture.

mandibular body fracture was fixed with 2 straight plate with 8 holes each and 16 screws, one in the tension area and one in the compression área; and left mandibular angle fracture was fixed with 1 straight plate with 4 holes and 4 screws. (Figure 3)
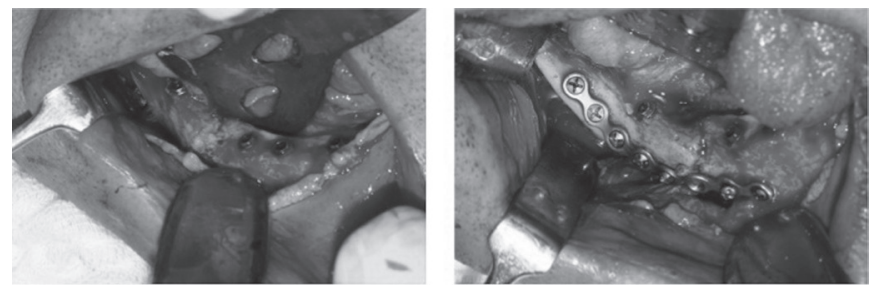

Figure 3. Trans operative - (Right). Dental implants installation; (Left) Adaptation and placement of reconstruction plate for mandibular fracture fixation.

Multifunctional transfer molding was performed after surgical suture, using a pre-fabricated guide and the index confection. Followed by the sequence of try out and preparation of implant prosthesis.

To determine dental occlusion scheme was previously evaluated le location of the implants, tissue volume dimensions, facial morphology, the intermaxilary relationship, taking into consideration the previus dental prostheses of the patient

The postoperative care included, hypercaloric and hyperproteic liquid diet and prescriptions followed the standard protocol with antibiotics (amoxicillin $500 \mathrm{mg}$ every 8 hours), anti-inflammatory (ibuprofen $300 \mathrm{mg}$ every 6 hours), and analgesic (acetaminophen 500 mg every 8 hours). On the third day after surgery a implant-supported prosthesis was installed, with $20 \mathrm{~N}$ torque.

On the 7th day post-operative, it was observed restoration of facial contours as well as the previous patient's occlusion. Radiographically was seen correct baseline realignment bone, as well as the maintenance of implant-supported prostheses.

After 6 and 18 months' post-operative the mandibular function was maintained as well as aesthetics. Radiographically, it was observed correct contour and bone like formation in the fracture region. (Figure $4,5$ e 6$)$

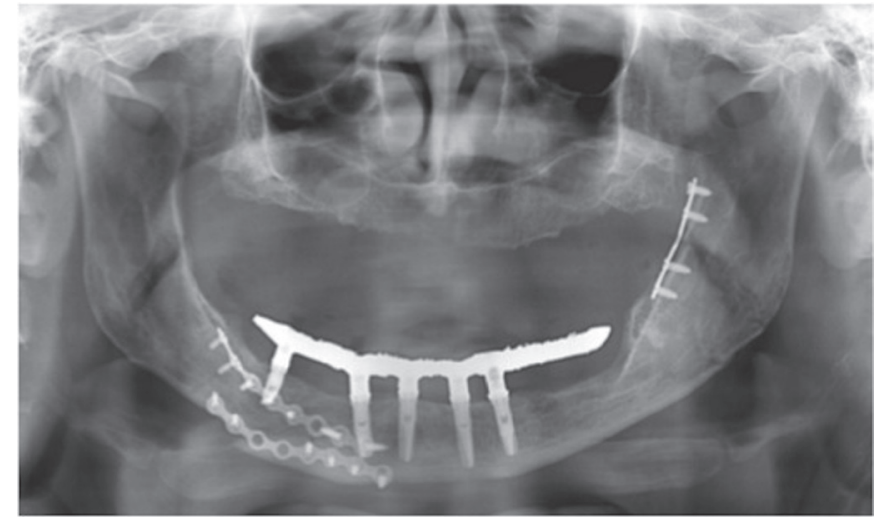

Figure 4. Six months' post-operative - Radiograph examination revealed proper plate and screws placement with correct basal realignment.
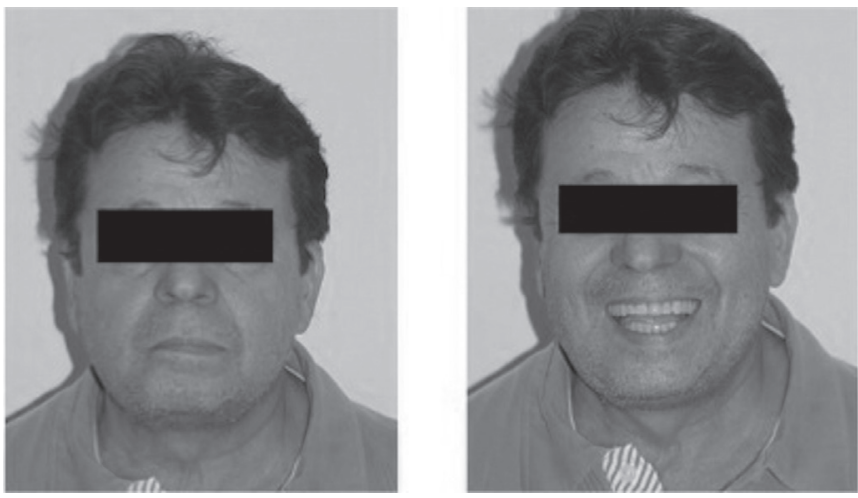

Figure 5. 18 months' post-surgery, bone and soft tissue healings were noted and no signs of mobility and/or infection in the mandibular and occlusal maintenance were observed.

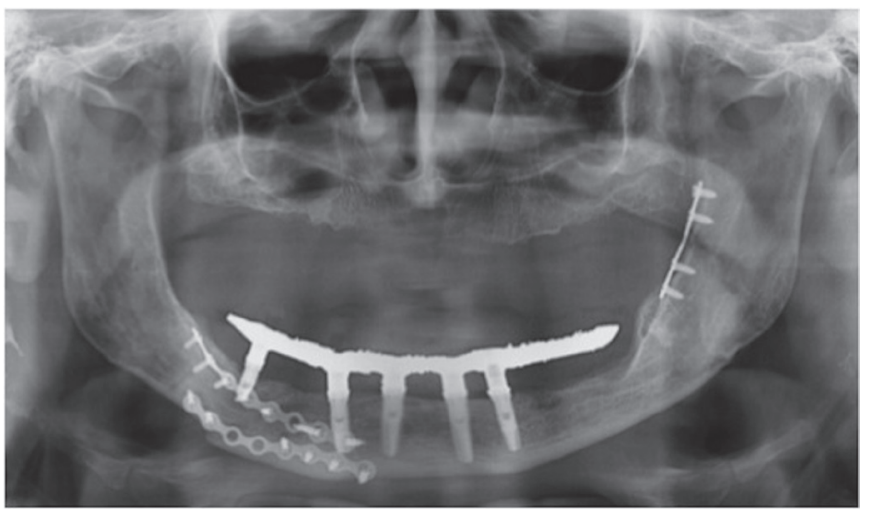

Figure 6. At 18 months' post-operative, radiograph examination revealed proper plate and screws placement with correct basal realignment and good healing process, without signs of infection

\section{DISCUSSION}

The size of the alveolar crest is determined by the presence of teeth; this means that in the absence of teeth alveolar bone resorption will occur. In edentulous patient, the replacement of natural teeth for a denture does not interrupt the bone resorption process, this results, among others, increasingly difficult stabilization of the prostheses ${ }^{(9)}$.

The use of dental implants are accepted as a safe and predictable method to assist in cosmetic and functional rehabilitation in patients with edentulous jaws ${ }^{(10)}$. However, in patients with severe resorption or mandibular fracture, local vascularization may be compromised, the indications for implants should be well evaluated in these patients ${ }^{(11)}$. In patients with mandibular fracture, open reduction and internal fixation of 
the fracture may further compromise local vascularization ${ }^{(12)}$.

Although the literature reports a decrease vascularization within the edentulous jaws, in special in bone fracture areas, which could present an unfavorable prognosis in cases of open reduction and internal fixation procedures, resulting in impairment of implant placement. In the case described, it was performed open reduction and internal fixation of a bilateral mandible fracture during the same surgical time, installation of implants and immediate loading prostheses, showing that this type of approach is possible.

A fact that may have contributed to the success of the treatment is the effect of immediate loading which allows the transmission of masticatory forces to the bone, and this promotes endosteal stimulation, and it can promote osteogenesis. Moreover, it stimulates the formation of new blood capillaries at the surgical site, favoring vascularization ${ }^{(13)}$.

Edentulous jaw fracture treated with open reduction an internal fixation with plates and screws, could be difficult, especially if longer plates and reconstruction plates are used, since the difficulty of adapt and stabilize the denture, due to this fact, the use of complementary therapy is acceptable to assist prostheses stabilization ${ }^{(12)}$. In view of this fact, the placement of dental implants in fractured jaws treated with plates and screws is completely correct, and the best approach to the resolution of this case.

In one case report, Romanos (2009)(14) demonstrated the success of treating a mandible fracture using a splint bar with implants on both sides of fracture, since this bar was fixed to implants, it promoted a rigid immobilization of fracture. Along with this therapy was prescribed antibiotics and soft diet. This fact is a justification to the success of the treatment applied to the right side of the mandible fracture of the described case, because an implant was installed after the fracture line and was joined this implant with the others installed before the fracture line with a metal bar, helping on the stability and healing of the fracture.

Immediate loading of implant supported prostheses, needs a welladjusted occlusion to prevent implants overload, which often leads to biomechanical complications. Implants overloading prevention helps to ensure long-term stability of implant-supported prostheses ${ }^{(15)}$. In our case, the occlusal adjustment was made with great care, distributing the masticatory forces, because treatment failure could not lead only to implant loss, but lead to the failure of the entire treatment, jeopardizing the fracture stabilization.

\section{CONCLUSION}

Functional prosthetic rehabilitation with dental implants and implantsupported prostheses with immediate loading system simultaneously with open reduction and fixation of mandibular fractures proved to be a good treatment option in this case, restoring function and aesthetics of the stomatognathic system.

\section{CONFLICT OF INTEREST AND FUNDING SOURCE}

None

\section{CLINICAL RELEVANCE}

On this article it is shown a bilateral mandibular fracture reduction simultaneusly to dental implants with immediante loading, to re-establish the masticatory function of the patient.

\section{References}

1. de Matos FP, Arnez MF, Sverzut CE, Trivellato AE. A retrospective study of mandibular fracture in a 40-month period. Int J Oral Maxillofac Surg. 2010;1:10-5. 2. Zachariades N, Mezitis M, Mourouzis C, Papadakis D, Spanou A. Fractures of the mandibular condyle: a review of 466 cases. Literature review, reflections on treatment and proposals. J Craniomaxillofac Surg. 2006;7:421-32.

3. Yamamoto K, Matsusue Y, Murakami K, Horita S, Sugiura T, Kirita T. Maxillofacial fractures in older patients. J Oral Maxillofac Surg. 2011;69(8):2204-10.

4. Sidal T, Curtis DA. Fractures of the mandible in the aging population. Spec Care Dentist. 2006;26:14-6.

5. Stacey DH, Doyle JF, Mount DL, Snyder MC, Gutowski KA. Management of mandible fractures. Plast Reconstr Surg. 2006;3:48e-60e.

6. Romanos G, Froum S, Hery C, Cho SC, Tarnow D. Survival rate of immediately vs delayed loaded implants: analysis of the current literature. J Oral Implantol. 2010;36:315-24

7. Dierens M, Collaert B, Deschepper E, Browaeys H, Klinge B, De Bruyn H. Patient-centered outcome of immediately loaded implants in the rehabilitation of fully edentulous jaws. Clin Oral Impl Res. 2009;20:1070-7.

8. Drago CJ, Lazzara RJ. Immediate occlusal loading of Osseotite implants in mandibular edentulous patients: a prospective observational report with 18-month data. J Prosthod. 2006;15:187-94.
9. Perdijk FBT, Meijer GJ, Bronkhorst EM, Koole R. Implants in the severely resorbed mandibles: whether or not to augment? What is the clinician's preference? Oral Maxillofac Surg. 2011;15(4): 225-31.

10. Stellingsma C, Meijer HJ, Raghoebar GM. Use of short endosseous implants and an overdenture in the extremely resorbed mandible: A five-year retrospective study. J Oral Maxillofac Surg. 2000;58:382-7.

11. Bradley JC. A radiological investigation into the age changes of the inferior dental artery. Br J Oral Surg. 1975;13:82-90.

12. Murata T, Yamashita Y, Kurokawa H, Takahashi T. Dental rehabilitation using an implant-supported overdenture after repair of a fracture in a severely resorbed edentulous mandible: A case report. Int J Oral Maxillofac Implants. 2004;19:749-52. 13. Misch CE, Hahn J, Judy KW, Lemons JE, Linkow LI, Lozada JL, et al. Workshop guidelines on immediate loading in implant dentistry. J Oral Implantol. 2004;30(5):283-8

14. Romanos GE. Nonsurgical prosthetic management of mandibular fracture associated with dental implant therapy: A case report. Int J Oral Maxillofac Implants. 2009;24:143-6.

15. Hsu YT, Fu JH, Al-Hezaimi K, Wang HL. Biomechanical implant treatment complications: A systematic review of clinical studies of implants with at least 1 year of functional loading. Int J Oral Maxillofac Implants. 2012;27:894-904. 